\title{
The political economy of industrialisation and industrial relations: a rejoinder
}

\author{
Sarosh Kuruvilla \\ School of Industrial Relations, Cornell University
}

It is always an honour when one's work receives a degree of attention entailing the production of a formal, written criticism. And this presents an opportunity for the original writer to clarify his/her argument, retract/modify that which has been cogently called into question, and to advance dialogue on issues regarding the interpretation of social reality about which reasonable people disagree. Gregor Gall's comments on my article present these very opportunities, and I welcome this chance to make a dialogical contribution that hopefully will promote the theoretical development of the field.

As I understand them, Gall's criticisms regarding my work are as follows:

1. The argument fails "to give weight to the contingencies of political economy" and "in particular political dynamics are given no weight in intervening and mediating the sphere of industrial relations." Most significantly, the argument unjustifiably ignores "a consideration of the role of labour as an active participant which can act independently rather than just be acted upon."

2. The argument mischaracterises industrial relations under ISI, ignoring suppressive elements.

3. "there is an overestimation of the degree and nature of change [in IR] from ISI to EOI. In part this stems from confusing further regulation of the labour market with suppression of workers' rights."

4. "the degree to which low cost labour is key to attracting FDI is exaggerated."

5. The argument exaggerates/mischaracterizes the shift in IR policy with change from EOI-Stage 1 to Stage 2 by claiming change in emphasis from cost-containment to work force flexibility and skills development as IR goals. Moreover the argument ignores the fact that "where any relaxation has taken place, this is as a result of the activity and growing strength of organised labour, allied to or part of a pro-democracy movement."

6. "Kuruvilla makes no attempt to explore the basis of how and why the oppositional force of organised labour develops and how this might be related to different regimes of industrialization or industrialisation in general."

7. "In regard to specific characteristics of Kuruvilla's ISI model, it is unhelpful to begin such an analysis with the period of independence for this underestimates the degrees of continuity in state policy towards labour given that the colonial period as often heavily coloured postcolonial 
IR."

8. The argument fails to recognise that "industrialisation strategies and industrial relations are not necessarily or always 'mutually reinforcing'."

These are all important criticisms that demand response. Criticism 2 through 5 (and 7) mainly deal with issues of classification and characterisation of change in the context of industrialisation strategy and IR change, while 1, 6, and 8 have more to do with issues of causation. Given this distinction, this response will be divided accordingly.

\section{Matters of classification and interpretation}

Gregor Gall puts forth two contentions regarding my interpretation of IR policy under ISI. The first raises an important methodological consideration in any comparative historical analysis, the issue of periodisation. Gall claims that it is not helpful to analyse IR policy under ISI starting with Independence because doing so "underestimates the degree of continuity in state policy towards labour given that the colonial period has often heavily coloured post-colonial IR." As an empirical claim, I could not agree more with this comment. Indeed, I've recently edited a book that seeks to uncover the influence of colonial labour policy on postcolonial IR systems in a variety of national and regional contexts [1]. Moreover, I recognize as much in the text of one of my works eg. "During the ISI phase, the focus of IR/HR policy was pluralistic, with little effort to tinker with inherited IR/HR institutions, which were primarily American" [2].

However, to the extent that Gregor Gall claims that the recognition of this fact is detrimental to my argument, I disagree. My argument is not so much that changes in industrialization strategies are the direct cause of changes in IR policy as that governments in my cases reconfigured IR policy to make it consonant with the industrialisation strategy. In the rare case where existing IR policy is indeed harmonious (eg. in the shift to independence and from traditional export policies to ISI), then no such changes will be evident.

Gall's second criticism of my interpretation of IR policy under ISI is that I mischaracterize it by understating/ignoring its suppressive elements. On this point, I would like to highlight the fact that I do use the term 'controlled pluralism' in an effort to avoid this pitfall. However, it is fair to say that I was not clear enough on this point. In using the term pluralism, I was attempting to capture the fact that governments under ISI in my cases placed little or no regulation on collective bargaining between unions and employers, leaving bargaining issues and outcomes to be left to the compromises between these two actors, their actions (eg. strikes and lock-outs) and the power distribution between them. 
However, as Gall states, it is indeed true that the concerned governments at the same time placed extensive restrictions on trade union formation and internal composition; and, as Deyo points out, these often had more to do with politics (especially regime stability) than economics [3]. What is clearly needed is a concept that captures this somewhat contradictory tendency of extensive control of working class organisations coupled with considerable voluntarism with respect to direct relations between employers and these organisations. Hiers, for one, has suggested the term 'ostensible voluntarism' [4].*

This confusion over classification of IR policy under ISI directly affects Gall's next criticism. I believe, namely that I exaggerate the extent of change in policy in the transition from ISI to EOI. By pointing out the extensive controls on labour organisation that existed prior to EOI, Gall claims that I overstate the degree to which the change in industrialization strategy was paralleled by a shift to a more suppressive IR policy because of my "confusing further regulation of the labour market with suppression of workers' rights." Let me state straightaway that I do not disagree with the claim that IR policy changes under EOI constituted further regulation, as the above paragraph suggests. However, I continue to contend that IR policy changed in a qualitatively significant way that was consonant with the change in industrialization strategy. With the shift to EOI, the governments in my cases expanded their regulatory focus beyond working class organisations and into the arena formerly left for the relatively free play of unions and management, especially bargaining and strikes/lockouts. While controls on labour organisations under ISI served mainly political goals, this change in policy under EOI \#1 entailed an important shift to economic concerns, namely cost-containment. It was not until the shift to EOI \#1 that, for example, the Malaysian government prohibited collective bargaining outcomes above the national minimum standards in export processing zones and took away labour's right to organise the first five years of a given firm's operations in the 'pioneer industries'. Thus, although IR policy under EOI \#1 represented an extension of regulation rather than a remaking of regulation anew, two points are significant:

1) the IR policy changes temporally coincided with the industrialisation strategy shift (suggesting a prima facie linkage between the two)

2) these policy changes constituted a qualitative shift toward a significant concern with containing costs, consistent with the successful use of EOI \#1.

A second related criticism of my classification of IR policy under EOI \#1 has less to do with its contrast/similarity with that under ISI and more to do with the importance of cost-containment under this industrialization strategy (and thus calls into question the linkage between IR and industrialisation strategies, even if IR policies suggest the goal of cost-containment). Gregor Gall argues that in my 
argument "the degree to which low cost labour is key to attracting FDI is exaggerated", and he highlights the importance of "glocalisation, [or] the establishment of MNC production facilities to service local markets" as "a countervailing tendency." If Gall means that factors in addition to low cost labour such as infrastructure, tax policy, etc. are important in attracting FDI, then I could not agree more.

However, three points are important here. The first is that pointing out the importance of these factors does not preclude low cost labour's significance. Second, although placing limitations on the right to strike in 'essential' industries can serve the goal of providing a reliable infrastructure, the only one of these enabling factors that IR policy (my dependent variable, after all) could have a substantial impact on is the cost of labour (and, besides, more extensive restrictions on strikes in essential industries were implemented at the time of the shift to EOI \#1); I never meant to suggest that IR policy and its promotion of low labour costs was the only initiative undertaken by the state to attract FDI but rather that there is evidence that IR policy was reconfigured in a way that would aid the successful undertaking of this industrialisation strategy (in addition probably to policies toward public sector industries, tax structure, etc.). Third, if Gall wishes to claim that cost containment is not of central importance to the pursuit of EOI \#1 (along with other factors), then I would have to disagree and point to the character of this strategy and the type of investment under it. Emphasising the export of labour-intensive, light manufactures, EOI \#1 makes it essential for states to deliver low cost labour to prospective investors.

A final criticism made by Gall regarding my classification of IR policy goals under different industrialisation strategies relates to EOI \#2. The claim is that I overstate the shift from costcontainment to work force flexibility and skills development because

a) wages and unit labour costs are still important;

b) labour repression is still widespread,

c) where any shift away from cost-containment has taken place, it has been due to the "growing strength of organised labour, allied to or part of a pro-democracy movement".

With respect to ' $c$ ', it is notable that one of my own cases (Singapore) is a clear example of a shift away from cost containment (witness the 12 percent per year increase in wages between 1979 and 1981 to drive out labour-intensive investors in favour of more capital-intensive ones) without the existence of either strong union pressure to do so or a democratisation movement. Perhaps Gall confuses my argument of a shift away from cost containment with the claim that repression and cost concerns fade altogether from national IR policy. Instead, however, I argue that goals of workforce flexibility and skills development come to the forefront under EOI \#2 i.e. their relative importance 
changes. This does not mean that repressive regulations and a concern for costs become irrelevant; indeed, repressive regulations, although usually less stringent than under

EOI \#1, can help to further these broader goals.

\section{Theoretical considerations}

Gall is clearly in disagreement with me given his interpretation of my causal argument and framework for approaching the linkage between industrialisation strategies and IR. He argues that a major weakness of my argument is that "political dynamics are given no weight in intervening and mediating the sphere of industrial relations". There is a particular concern that labour is accorded no agency and that my argument "makes no attempt to explore the basis of how and why the oppositional force of organised labour develops and how this might be related to different regimes of industrialisation or industrialisation in general". Moreover, in part because I ignore these political factors, Gall claims that my argument fails to recognise that "industrialization strategies and industrial relations are not necessarily or always 'mutually reinforcing'." Thus, Gall suggests that the introduction of political factors could serve to complicate my framework for analysis and provide it with more explanatory power.

In response to these criticisms, a first point is that I do not hold the belief that IR and IS are always mutually reinforcing. Although my earliest work might have suggested as much, my latest article on this topic indicates that I am making a normative policy argument based on an empirically identified linkage in my particular cases. I open my conclusion with the following: "The results of this paper suggest that congruence between IS and IR/HR policy goals is an important precondition for successful economic development" [6]. Thus, rather than arguing that IR and IS are always mutually reinforcing, I instead argue that they should be in order to promote successful economic development.

A second point is that I did not intend in any of my work to offer a generalizable framework for the study of industrialization and IR, but have saved such a task for later work [7]. Thus, when Gall states that he "has sought to assert the importance of political contingency and dynamics to establish the proper and full context of political economy for a credible analysis of the relationship between industrialisation and IR in south and south-east Asia," I believe that Gall makes an important contribution toward such a generalisable framework. My goals were more modest ie., to suggest that the IR and IS are often mutually reinforcing. And I chose to focus my attention on the relationship between the two, rather than to create a generalisable theory. ${ }^{* *}$ 
A third and final point is that, while I agree that my model undertheorises political factors (especially for the purposes of more generalizable analysis), I do not think it is true that "political dynamics [including labour action] are given no weight in intervening and mediating the sphere of industrial relations". Gregor Gall himself quotes me as saying that "institutional arrangements used to meet national IR/HR policy goals are dependent on the choices governments make, and these choices are constrained by political conditions (for example, the power of the ruling party and the influence of unions) as well as previous institutional history" [9] and immediately follows this quotation by suggesting that I argue that "the government and the state" are the sole determiners of IR policy, which ignores "a consideration of the role of labour as an active participant which can act independently rather than just be acted upon." As my own quotation indicates, though, this is clearly not the case: rather than acting in a vacuum, governments "are constrained by political conditions (for example, the power of the ruling party and the influence of the unions)" (emphasis added). In fairness, though, this nod to labour's agency is rather brief and probably could have been better explained. ${ }^{\dagger}$

Nonetheless, this quotation clearly indicates that it is not accurate to argue that "political dynamics are given no weight in intervening and mediating the sphere of industrial relations" (emphasis added). Yet, there are more indications. One example is my discussion of the Philippines where my analysis integrates political factors to explain how political change resulted in different IR policies to pursue the same end of cost containment:

"Although the focus of the cost-containment- oriented labour policy was consistent with a lowcost primary EOI strategy, the institutional industrial relations arrangements varied across different political regimes. During the Marcos dictatorship labour relations were extremely repressive. During the Aquino and Ramos governments, in contrast, democratisation led to the removal of the restrictive IR/HR policies of the Marcos era. However, the liberalisation of labour regulations to make union formation easier has resulted in an increasingly fragmented labour movement. Furthermore, declines in real wages and job security, the downward revision in labour standards, and extremely weak union movement indicate that IR/HR policies have helped sustain the low-cost development strategy [10].

\section{Conclusion}

I thus agree with Gregor Gall's general call for a more comprehensive theory that explains the relationship between IS and IR, especially one that pays greater attention to political dynamics and unions themselves, and the many assertions that Gall has made in his comment on my article is clearly a 
step in the right direction. My goals have been much more modest than what he gives me credit for. Although I recognise the importance of political factors, I have not developed on this aspect in my work because I intended to focus on the link between economic issues and industrial relations, and my work suggests that there has been a 'fit' between these.

\section{References}

1. Kuruvilla, S. and Mundell, B., Colonialism and Industrial Relations in Developing Countries, New York: JAI Press, Forthcoming 1998.

2. Kuruvilla, S., 'Linkages Between Industrialization Strategies and Industrial Relations and Human Resource Policies: Singapore, Malaysia, Philippines, and India', Industrial and Labor Relations Review, 1996, 49:4, p. 646 emphasis added.

3. Deyo, F., Beneath the Miracle: Labour Subordination in East Asian Development, University of California Press, Berkeley, 1989.

4. Hiers, W., 'Malaysia' in S. Kuruvilla and B. Mundell (eds), op. cit.

5. Kuruvilla, 1996, op. cit.

6. Ibid., p. 653, emphasis added.

7. Hiers, W. and Kuruvilla, S., Economic Development and Industrial Relations: A Theoretical Reprise, Unpublished Manuscript, Institute of Collective Bargaining, Cornell University 1998.

8. Kuruvilla, 1996, op. cit. P. 653.

9. Ibid., p. 635 .

10. Ibid., p. 649.

* It's also notable that I attempted to avoid this pitfall in the latest of my work reviewed by focusing on IR policy goals rather than on classifications of the system as a whole (eg. controlled pluralism), the argument being that ISI \#1 and \#2 are consistent with policy goals of stability and productivity enhancement [5]. This of course does not excuse my lack of detail regarding state regulation of unions, but it does illustrate that the descriptive term (eg., ostensible voluntarism) is not as important as making the functional linkage between the goal of stability and the existence of labour controls that permit and albeit limited right to organise and take collective action coupled with labour-management relations regulations that permit relatively unconstrained bargaining between the two.

** One might argue that this is an unfair counter, given that I state that "There is some evidence that the arguments made in this paper are generalisable to other Asian countries" [8] and then went on to cite a few supportive studies of Taiwan, Korea, Hong Kong, and Indonesia. However, given this limited statement, generalisability was clearly not an important concern and, thus, to the extent that Gall brings out the importance of other salient factors via study of these additional countries, he makes an important contribution towards a generalisable framework but not one directly critical of my argument on its own terms.

t One illustration would be Singapore, where the strength of the ruling party was due in part to the degree of organised labour's incorporation into the regime, which resulted in the National Trade Union 